\title{
Physical impact on crop yield
}

\section{SOLAR-CAUSED FLUCTUATIONS IN EARTH'S MAGNETIC FIELD AND STATISTICAL WHEAT (Triticum L., 1753) YIELD}

\author{
I.Yu. SAVIN ${ }^{1,2}$, O. LEO ${ }^{3}$
}

${ }^{1}$ V.V. Dokuchaev Soil Science Institute, Federal Agency of Scientific Organizations, 7/2, Pyzhevskii per., Moscow, 119017 Russia, e-mail savin_iyu@pfur.ru;

${ }^{2}$ Agro-Technological Institute of Peoples' Friendship University of Russia, 8/2, ul. Miklukho-Maklaya, Moscow, 117198 Russia;

3 Joint Research Centre of European Commission, Via Enrico Fermi, 2749, 21027 Ispra VA, Italy, e-mail olivier.leo@jrc.ec.europa.eu

Received January 29, 2016

\section{Abstract}

In the light of the latest scientific achievements the great role played by the geomagnetic processes in a variety of phenomena in the world (in the atmosphere, the biosphere and the social sphere) becomes more and more apparent. It is known that the temporal variation of the geomagnetic field is determined by interplanetary processes, the Earth's rotation, as well as fluctuations in solar activity. In this connection, the data on the phenomena on the Sun and changes in the Earth's magnetic field have been widely used in various fields of science and technology and in solving many applied problems. The impact of artificial magnetic fields on the crop growth was demonstrated in the vast number of scientific publications. However, the effect of fluctuations of the natural Earth's magnetic field caused by the influence of the Sun on the crop yield is still practically unknown. The evaluation of the level of correlation was conducted between solar-caused fluctuations in Earth's magnetic field and statistical wheat yield for countries where the crop is grown. This crop is cultivated in many countries of the world, which allows to include in the analysis regions with different natural and agronomic conditions. Actual information about the wheat yield was obtained from FAO's statistical database FAOSTAT (http://faostat.fao.org/site/339/default.aspx). As an indicator of the global geomagnetic activity $K_{p}$ index was used. $K_{p}$ index values were averaged for individual days, months, and years. The average value of the index is rounded to the closest standard value of it. Monthly average $\mathrm{K}_{\mathrm{p}}$ values were used to calculate the average values of the index for the period of wheat growth. As a result, a statistically significant correlation between the annual change in the yield of wheat and solar-caused changes of Earth's magnetic field was found. The coefficient of correlation in some countries reaches a sufficiently high value. The highest rates of positive correlation set for Belgium $(r=0.7)$, Kenya, Mali and North Korea (at $r=0.6$ for each country). The negative relationship is most pronounced in Russia $(r=-0.8)$, Ukraine, Moldova, Uzbekistan and Bolivia $(r=-0.7$ for each). Specificity of the manifestations of the correlation around the world suggests the presence of both direct and indirect (through a change in the meteorological conditions) impact of fluctuations of the geomagnetic field on crop yield. In the case of direct impact, the observed correlation of crop yield with the $\mathrm{K}_{\mathrm{p}}$, index averaged for the growing season, should be expressed more clearly than with $K_{p}$ index, averaged for the year. Our analysis revealed more countries with a statistically significant correlation in the case of usage of seasonal $\mathrm{K}_{\mathrm{p}}$ index. It is often observed the following situation: in the case of a negative correlation of crop yield with the annual value of the $\mathrm{K}_{\mathrm{p}}$ value of $r$ increases when using the seasonal $K_{p}$ index, and for a positive relationship between crop yield and the annual value of the $\mathrm{K}_{\mathrm{p}}$ index $\mathrm{r}$ in the case of the seasonal index decreases (sometimes up to statistically insignificant values). The latter can be explained by the inertia of the reaction of atmospheric processes on the impact of fluctuations of geomagnetic activity, which is similar to that in relation to the impact of El Nico and La Nica on changes in air temperature and precipitation (R. Stefanski, 1994). A more confident conclusion about the importance of the direct and indirect effects can be apparently obtained by carrying out a similar analysis for other crops, as well as through a more precise allocation of time during the growing season in each year and growing region.

Keywords: solar activity, solar-terrestrial linkage, wheat yield, geomagnetic field, crop yield variability

Sun effects on the life on Earth have been discussed in the studies per- 
formed by the scientists of almost all generations since the dawn of science. Alexander L. Chizhevsky's (1897-1964) works gave this research area a huge boost. One cannot but agree with L.V. Golovanov's opinion: "A.L. Chizhevsky's achievements can be compared with the Nicolaus Copernicus's deed. Similar to Copernicus who saw the actual Earth's movement in Space, he, in turn, found that all the terrestrial pulsates in the rhythm of the Sun <...> A.L. Chizhevsky completed the break-up of geocentrism in its last refuge - in the science of life" [1, p. 7].

In his works, A.L. Chizhevsky specified repeatedly that the effects of the Sun on terrestrial processes are versatile, and that many terrestrial processes change their "normal" behavior under its influence [2[. In the light of the latest scientific achievements, the great role played by geomagnetic processes in the variety of terrestrial phenomena (in the atmosphere, biosphere, and social sphere) becomes more and more apparent [3-5]. Currently, temporal variations of geomagnetic field are known to be largely determined by interplanetary processes, the Earth's rotation, and solar activity fluctuations. In this regard, the data on the phenomena on the Sun and changes in the magnetic field of the Earth are being widely used in various fields of science and technology and in solving numerous applied problems.

The impact of magnetic field on crop growth has been studied for a long time. Thus, one can easily find a great number of scientific publications which demonstrate the positive impact of artificial magnetic fields on the crops [4, 816]. Effect is seen in almost all stages of plant development [17, 18]. In addition, magnetic fields are noted to have effect on various plant organs [19].

At the same time, the effect of natural solar-caused magnetic field fluctuations on the crop yield is still poorly understood.

In our research, we made an attempt to estimate the correlation between solar-caused fluctuations in the Earth's magnetic field and wheat yields for the countries of the world where the crop is grown.

Technique. The data on the actual wheat yields in the countries obtained from statistical database FAOSTAT (Food and Agriculture Organization, FAO) were analyzed [20]. Based on a preliminary assessment of the data quality, the countries were divided into groups. Group I included the countries where wheat crops were practically absent or the data quality was doubtful (suspicions of the low data quality are based, as a rule, on the presence of too great differences in annual yields, or on the same yields reported for several consecutive years). Group II included the countries where statistical data visually look reliable for the entire period of analysis (visually determined data reliability does not exclude the probability of errors). The countries with visually reliable statistical data for the last 15 years only were combined as Group III. In addition, the countries where spring and winter wheat is grown within two seasons were included in a separate group (IV) (FAO statistical database provides the data on wheat yields not specifying winter and spring crops for these countries).

The quality of statistical information was taken into account in the analysis of correlation between solar-caused fluctuations in the Earth's magnetic field and wheat yields. The crop growing seasons in the countries which was determined using the averaged data of FAO was also taken into account [20].

The values of $\mathrm{K}_{\mathrm{p}}$ index for the period of this study were obtained from the website of the USA National Geophysical Data Center (ftp://ftp.ngdc.noaa.gov/STP/GEOMAGNETIC_DATA/INDICES/). $\mathrm{K}_{\mathrm{p}}$ index values were averaged for individual days, months, and years. The average index value was rounded to the closest standard index value. Average monthly $\mathrm{K}_{\mathrm{p}}$ values were 
used to calculate average index values for the period of wheat growth.

All initial information (index values and data on wheat yields) was first converted to series of data differences (differences with the previous year were calculated for annual data). Then, these series were converted to series of difference signs. Thus, at the end of conversion, each sequence of data contained the " 1 ", "0", or "1" values only. These conversions were carried out to identify the most general regulations only and at the same time to smooth out the effects of statistical data errors on the results of the research.

Correlation between the yields and geomagnetic activity was assessed using nonparametric correlation analysis based on generally accepted Kendal (tau_b) and Spearman $(\rho)$ approaches. Only the values of correlation coefficient significant at the levels of 0.005 and 0.001 were taken into account.

Results. Irregular variations in the Earth's magnetic field are created by the changes in magnetosphere exposed to solar plasma flow and by the interaction of magnetosphere and ionosphere. To characterize these variations in magnetic field, indices of geomagnetic activity are commonly used. In various historical periods, several dozen indices of solar and geomagnetic activity characterizing its various aspects have been proposed. In this study, $\mathrm{K}_{\mathrm{p}}$ index was used as an indicator of global geomagnetic activity. It was proposed over 60 years ago and has been widely used in ionospheric and magnetospheric experiments $[6,21$, $22] . K_{p}$ is a planetary average of $K$ indices, which in turn are calculated according to the data of a specific terrestrial observatory for the 3-hour interval. The index is a value from 0 to 9 for each 3 -hour interval. To calculate the index, the value of magnetic field for 3 hours is taken, the regular part determined by calm days is deducted from it, as well as the value obtained by the special table and specific to each station. Planetary $K_{p}$ index is calculated as the average value of $\mathrm{K}$ indices estimated at 13 geomagnetic stations located between $44^{\circ}$ and $60^{\circ}$ north latitude and $44^{\circ}$ and $60^{\circ}$ south latitude.

Wheat was selected as the object of the study due to the fact that this crop is cultivated in many countries around the world. Thus, the regions with different natural conditions and farming techniques used may be included in the analysis. Correlations between statistical wheat yields and the values of $\mathrm{K}_{\mathrm{p}}$ indices averaged for the year and the growing season were analyzed.

A large number of countries were characterized by statistically significant correlation between the changes in annual yields and $\mathrm{K}_{\mathrm{p}}$ values (Fig. 1, A). Here, the areas of positive and negative correlations were identified clearly enough. Thus, a negative correlation was observed in the area which covers the territory from Eastern Europe to India and Bangladesh. Also, the correlation coefficient was negative for Southern Africa (Lesotho) for the North Pacific (Japan-Mexico). Maximum negative correlation coefficients were found for Albania $(r=-0.9)$, Lesotho $(r=-0.7)$, Lithuania, Bulgaria, Turkey, Russia, and Japan (about $r=-0.6$ for all countries).

Positive correlation was typical of almost all countries in Africa, Brazil, New Zealand, and some countries of Western Europe. Maximum positive correlation coefficients were found for Brazil $(r=0.7)$, Algeria $(r=0.7)$, Belgium, Zambia, and Zimbabwe ( $r=0.6$ for all countries).

Analysis of correlations between the changes in the yields and $K_{p}$ indices averaged only for the wheat growing season demonstrated a similar distribution (see Fig. 1, B). Negative and positive correlation areas were retained in general. At the same time, there was a notable increase in the number of countries with statistically significant correlation. The highest rates of positive correlation were estimated for Belgium $(r=0.7)$, Kenya, Mali, and North Korea $(r=0.6$ for each country). Negative correlation was most pronounced in Russia $(r=-0.8)$, 
Ukraine, Moldova, Uzbekistan, and Bolivia ( $r=-0.7$ for each of the countries).

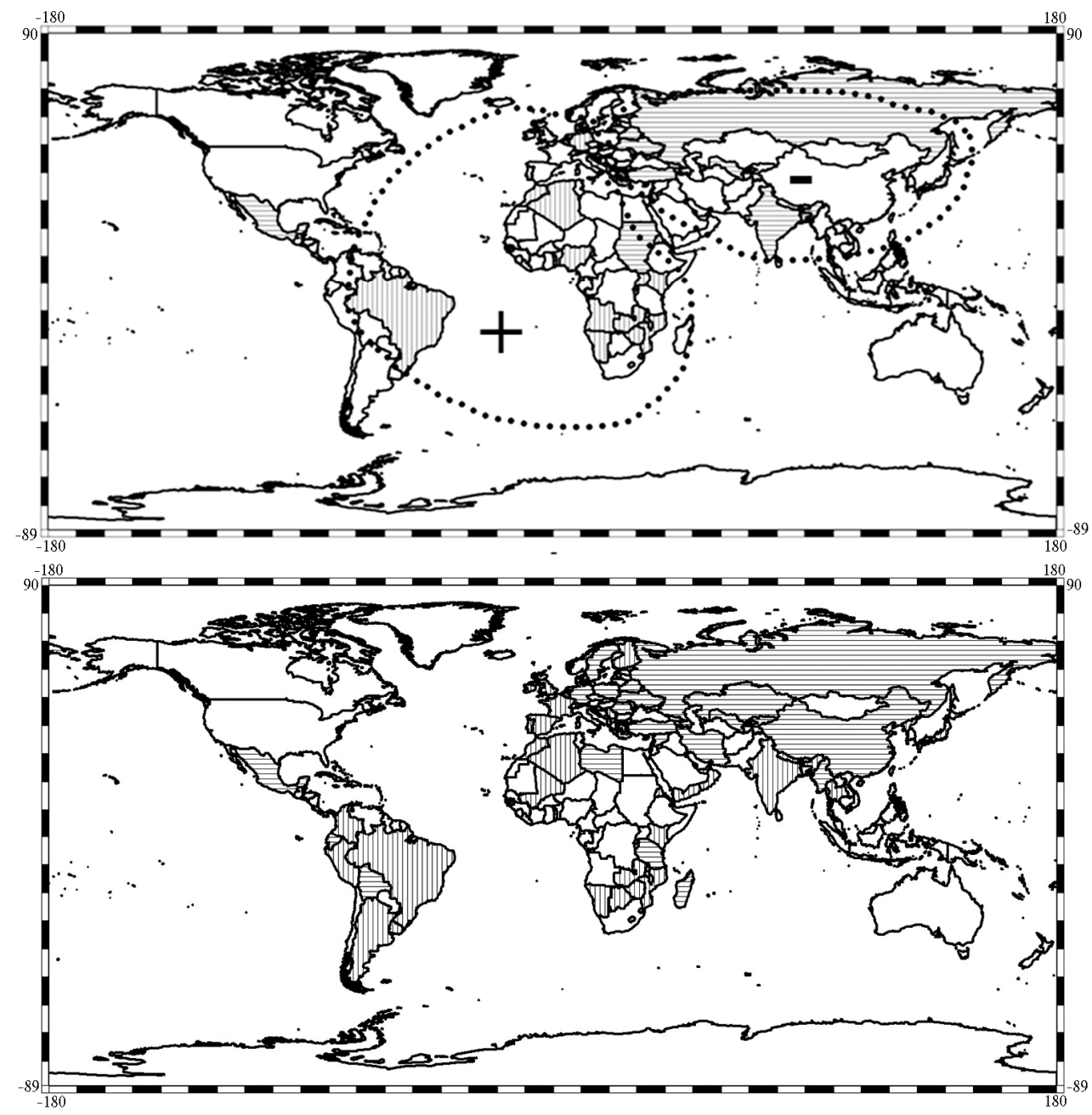

Fig. 1. Correlation between statistical wheat (Triticum L.) yeilds for the countries (according to FAOSTAT, 1961-2005) and geomagnetic activity indices $\mathbf{K}_{\mathbf{p}}$ averaged for calendar years (A) and annual growing seasons (B) (horizontal and vertical shading mean negative and positive correlations, respectively; dotted lines mark main correlation areas).

Several examples of yield and $\mathrm{K}_{\mathrm{p}}$ index variations are presented in Fig. 2. It is necessary to note that for some countries (e.g., New Zealand, Bangladesh, Sudan), statistically significant correlations with annual index $\mathrm{K}_{\mathrm{p}}$ values disappeared in the analysis of correlations with seasonal indices. For some countries, there was a change of the correlation coefficient sign. Thus, correlation coefficients between wheat yields and annual $\mathrm{Kp}$ values were negative, while they were positive between wheat yields and the seasonal values. At the same time, attention is drawn to the fact that the change of the sign (positive annual to negative seasonal) has not been observed.

In addition, the cases of lower seasonal values of correlation coefficients versus annual ones are of interest. For example, this took place in the case of Brazil $\left(r_{\text {annual }}=0.7\right.$ and $\left.r_{\text {seasonal }}=0.4\right)$, Algeria $\left(r_{\text {annual }}=0.7\right.$ and $\left.r_{\text {seasonal }}=0.3\right)$, Albania $\left(r_{\text {annual }}=-0.9\right.$ and $\left.r_{\text {seasonal }}=-0.6\right)$, and some other countries.

Moreover, it should be noted that the values of correlation coefficients increased with shortened observation sequence lengths in many countries. In many cases, the maximum correlation is observed for the period of 1990-2004. 
For example, correlation coefficients $(r)$ were -0.9 in $1990-2004$ and just -0.3 in 1963-2004 for Albania; $r$ values were -0.4 in 1963-2004 and increased to -0.7 in 1990-2004 for Lesotho. In some cases, correlations that were statistically significant for the 1990-2004 period became insignificant for the period of 1963-2004. Conversely, correlation coefficient values for 1963-2004 were greater versus the period of 1990-2004 in some countries (Cyprus, Namibia, Germany, Switzerland).

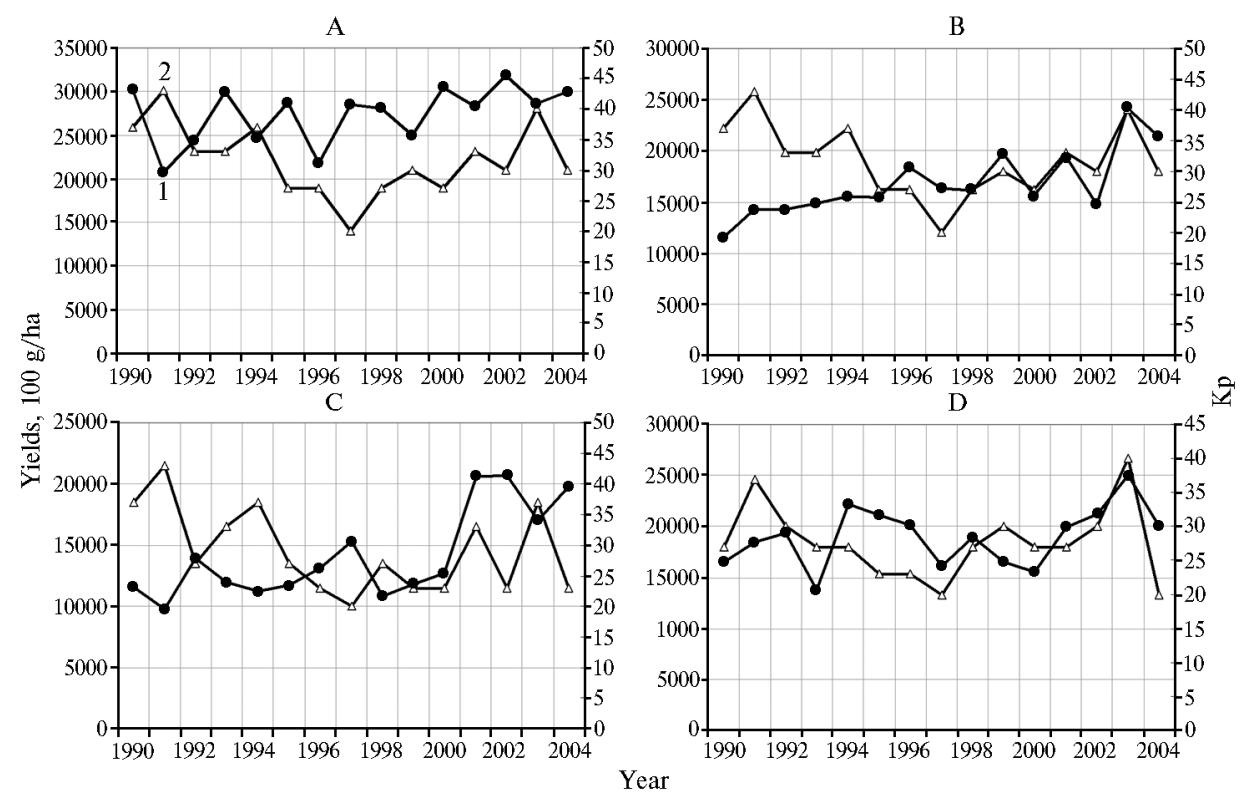

Fig. 2. Examples of statistical wheat (Triticum L.) yields (1) in various countries (according to FAOSTAT, 1990-2004) and corresponding geomagnetic activity index $\mathbf{K}_{\mathbf{p}}(2)$ values averaged for every calendar year (A, B) or for annual wheat growing seasons only $(\mathrm{C}, \mathrm{D})$ : A - Albania, B - Brazil, C Kenya, D - Russia.

A large number of countries with statistically significant correlations between the geomagnetic index and wheat yields show the influence of global geomagnetic field fluctuations on this crop productivity. Potentially, this effect may be due to both direct and indirect impact (through the effects on meteorological conditions) on plant growth.

The presence of countries with no significant correlation can be partially explained by unreliable statistics. In some countries, wheat is grown for two seasons in a year, and statistical data are presented in the FAO database in summary which can also affect the study results. In some cases, the lack of correlation seems due to the fact that wheat yields are mostly influenced not by meteorological conditions but by other factors (such as the amount of fertilizers applied, or a failure to comply with agricultural techniques of crop cultivation). In addition, the used indicator of the Earth's geomagnetic field is a good indicator of the temporal, but not spatial variation. Theoretically, temporal variation can manifest itself differently in the regions with low or high geomagnetic background which can also affect the presence or absence of the dependence analyzed.

The effects of geomagnetic field fluctuations on the functioning of baric atmospheric formations have been studied by many authors [5, 23-26]. The results of earlier studies have been mentioned in A.L. Chizhevsky's publications [2]. The authors conclude that high-level magnetic activity results in cyclone deepening, in winter (cold) period especially. In addition, they hypothesize an 
increase in the contrast between atmospheric baric formations (cyclone deepening and anticyclone strengthening) as a result of increased Earth's magnetic field.

These results can explain the presence of regions with positive and negative correlations between $K_{p}$ index and wheat yields. Analysis of wheat cultivation period in various countries shows that wheat is grown in the winter months in most countries, with few exceptions. Cyclone deepening in the years with high-level magnetic field should be expressed in an increase in precipitation which in turn results in an increase in wheat yields and, consequently, in the emergence of positive correlations between this parameter and the value of $\mathrm{K}_{\mathrm{p}}$. Within the main zone of negative correlation, winter meteorological conditions are determined by anticyclone dominance (the so-called Siberian maximum). Strengthening anticyclones in this region can result in a decrease in precipitation, snow depth and lower air temperatures. All this creates unfavorable conditions for the period of winter dormancy and beginning of active vegetation of spring wheat thus reducing the yield. Therefore, the regions with negative correlations between wheat yields and $\mathrm{K}_{\mathrm{p}}$ indices may appear.

In the case of direct impact of geomagnetic field fluctuations on wheat growth, the observed correlation between the crop yield and $\mathrm{K}_{\mathrm{p}}$ index averaged for the growing season should be expressed more clearly than with $K_{p}$ index averaged for the year. Our analysis revealed more countries with a statistically significant correlation with using of seasonal $\mathrm{K}_{\mathrm{p}}$ indices. However, this is followed by a regularity: in many countries, $r$ values increased where a negative correlation of crop yields with the annual $\mathrm{K}_{\mathrm{p}}$ value was found, while $r$ values decreased (down to statistically insignificant values sometimes) with the positive correlation between crop yields and the seasonal index. The latter can be explained by the inertia of the reaction of atmospheric processes against the impact of geomagnetic activity fluctuations. That is the effect of high geomagnetic background for one period of a year may affect the nature of atmospheric processes in the other period. A similar effect was noted, for example, when analyzing the impact of El Niño and La Niña on the changes in air temperature and precipitation [27].

Thus, a correlation between the changes in wheat yields and solar-caused fluctuations in the Earth's magnetic field has been found. Despite the large number of factors associated with the crop yield, the value of coefficient of correlation reaches rather high values in some countries. Specificity of correlation manifestations around the world suggests the presence of both direct and indirect (through a change in meteorological conditions) impact of geomagnetic field fluctuations on wheat yields. A more confident conclusion on the importance of direct and indirect effects can be apparently obtained by carrying out a similar analysis for other crops and through a more precise specification of the growing season timing in individual years and growing regions.

\section{REF ER E N C ES}

1. Golova nov L.V. Kosmicheskii determinizm Chizhevskogo (predislovie $k$ knige: Chizhev-skii A.L. Kosmicheskii pul's zhizni: Zemlya v ob"yatiyakh Solntsa. Geliotaraksiya) [The Chizhevsky's cosmic determinism - Forewooord to Chizhevsky A.L Cosmic pulse of life. Earth in the embrace of the Sun. Heliotaraxy]. Moscow, 1995: 5-29 (in Russ.).

2. Chizhevski i A.L. Kosmicheskii pul's zhizni: Zemlya v ob"yatiyakh Solntsa. Geliotaraksiya [Cosmic pulse of life. Earth in the embrace of the Sun. Heliotaraxy]. Moscow, 1995 (in Russ.).

3. Courtillot V., Le Mouel J., Ducruix J., Cazenave A. Geomagnetic secular variation as a precursor of climate change. Nature, 1982, 297: 386-387 (doi: 10.1038/297386a0).

4. Minorsky P.V. Do geomagnetic variations affect plant function? Journal of Atmospheric and Solar-Terrestrial Physics, 2007, 69(14): 1770-1774 (doi: 10.1016/j.jastp.2006.12.004).

5. Lockwood M., Foste r S. Long-term variation in the magnetic fields of the sun and possible implication for terrestrial climate. Proc. $1^{\text {st }}$ Solar and Space Weather Euroconference (Spain, 
September 25-29, 2000). Tenerife, 2000: 85-94.

6. M a y u d P.N. Derivation, meaning and use of geomagnetic indices. Geophysical Monograph V. 22. Am. Geophys. Union, Washington, D.C., 1980 (doi: 10.1002/9781118663837.fmatter).

7. G e orgi eva K., Ki rov B., Javarai a h. Solar asymmetry and Sun-Earth connection. Proc. ISCS 2003 Symposium (Slovakia, 2003, 23-28 June). Bratislava, 2003: 323-328.

8. S e regina M.T., Pavlova N.A., Ali mova Z.I. Elektronnaya obrabotka materialov, 1991, 1: 67-71 (in Russ.).

9. V e r b i t s k y a S.V. Predposevnaya obrabotka semyan fasoli ozonom i magnitnym polem. Avtoreferat kandidatskoi dissertatsii [Pre-sowing ozone and magnetic stimulation of kidney beans. PhD Thesis]. Zernograd, 2001. Available: http://www.dissercat.com/content/pred-posevnaya-obrabotkasemyan-fasoli-ozonom-i-magnitnym-polem\#ixzz4Biv4F0j5 [Accessed 20 January 2016] (in Russ.).

10. L e d n e v V.V. Possible mechanism for the influence of weak magnetic fields on biological systems. Bioelectromagnetics, 1991, 12(2): 71-75.

11. Pietruszewski S.T. Effect of magnetic seed treatment on yields of wheat. Seed Sci. Technol., 1993, 21(4): 621-626.

12. Phirke P.S., Kubde A.B., Umbarkar S.P. The influence of magnetic field on plant growth. Seed Sci. Technol., 1996, 24(2): 375-392.

13. Pitt man U.J. Effect of magnetic treatment on yield of barley, wheat and oats in Southern Alberta. Can. J. Plant Sci., 1977, 57: 37-45.

14. Ruzič R., B erden M., Jerma I. The effects of oscillating electromagnetic fields on plants. Proc. First World Congress on the Bioeffects of Electricity and Magnetism on the Natural World (UK, 1-6 October, 1998). Madeira, 1998: 58-63.

15. Carbone 11 M.V., Martinez E., A may J.M. Stimulation of germination in rice (Oryza sativa L.) by a static magnetic field. Electromagnetic Biology and Medicine, 2000, 19(2): 121-128.

16. Aksenov S.I., Bulychev A.A., Grunina T.Yu., Turovetski i V.B. Biofizika, 2000, 45: 737-745 (in Russ.).

17. M affe i M.E. Magnetic field effects on plant growth, development, and evolution. Front. Plant Sci., 2014, 5: 445 (doi: 10.3389/fpls.2014.00445).

18. Payez A., Ghanati F., Behmanesh M., Abdolmaleki P., Hajnorouzi A., Ra$\mathrm{jabbeigi}$ E. Increase of seed germination, growth and membrane integrity of wheat seedlings by exposure to static and a 10-KHz electromagnetic field. Electromagn. Biol. Med., 2013, 32(4): 417-429 (doi: 10.3109/15368378.2012.735625).

19. Aleman E.I., Mbogholi A., Boix Y.F., Gonzalez-Ohnedo J., Chalfun A. Effects of EMFs on some biological parameters in coffee plants (Coffea arabica L.) obtained by in vitro propagation. Polish J. Environ., 2014, Stud. 23: 95-101.

20. Rochalska M. The influence of low frequency magnetic field upon cultivable plant physiology. Nukleonika, 2008, 53: 17-20.

21. FAOSTAT, 2006. Available: http://faostat.fao.org/ [No date].

22. B a r t e ls J. The standardized index, Ks, and the planetary index, Kp. IATME Bull. Int. Union of Geod. and Geophys. Publ. Off., Paris, 1949, $12 \mathrm{~b}$.

23. S i e b e rt M. MaBzahlen der erdmagnetischen Aktivitat. In: Encyclopedia of physics (Handbuch der Physik). S. Flügge (ed.). V. 49/3. Springer-Verlag, 1988: 206-275.

24. K i s h c h a P.V., D $\mathrm{m}$ i t $\mathrm{r}$ i e v a I.V. Secular variations of solar-geomagnetic links and meteorological parameters. Proc. Conference on Modern Problems of Solar Circularity (26-30 May, Russia, 1977). St. Petersburg, 1997: 116-120.

25. S ve n s mark H. Influence of cosmic rays on Earth's climate. Phys. Rev. Lett., 1998, 81: 5027-5030 (doi: 10.1103/PhysRevLett.81.5027).

26. Tinsley B.A. Influence of solar wind on the global electric circuit, and inferred effects on cloud microphysics, temperature, and dynamics in the troposphere. Space Sci. Rev., 2000, 94: 231-258 (doi: 10.1023/A:1026775408875).

27. E $1 \mathrm{~s} n$ e r J., Kalvakov S. Hurricane intensity changes associated with geomagnetic variation. Atmos. Sci. Lett., 2001, 2(1-4): 86-93 (doi: 10.1006/asle.2001.0043).

28. Stef a nski R. El Nino: background, mechanisms, and impacts. In: Major world crop areas and climatic profiles. Agricultural Handbook 664. USDA, Washington, D.C., 1994: 247-252. 